\title{
Identification of RING-H2 Gene Candidates Related to Wood Formation in Poplar
}

\author{
Guimin Tong, Hongmei Shen, Shenquan Cao, Wenjing Xu, Xujun Ma and Yuxiang Cheng *(1) \\ State Key Laboratory of Tree Genetics and Breeding, Northeast Forestry University, Harbin 15000, China \\ * Correspondence: chengyuxiang@nefu.edu.cn; Tel.: +86-451-8219-2153
}

Received: 23 June 2019; Accepted: 13 August 2019; Published: 17 August 2019

\begin{abstract}
RING-H2 genes, the most abundant RING-type genes encoding putative ubiquitin ligase E3, are involved in diverse biological processes. Whether RING-H2 genes are related to wood formation remains to be identified in trees. In this study, we identified 288 RING-H2 genes in Populus trichocarpa, and found that the segmental and tandem duplication events contributed to RING-H2 gene expansion. Microarray dataset (from Affymetrix poplar genome arrays) showed that 64 of the 249 RING-H2 genes were highly or preferentially expressed in stem xylem. According to the AspWood RNAseq dataset, the transcription levels of genes PtrRHH21, 33, 48, 69, 88, 93, 94, 121, $141,166,175,192,208,214,250$ and 257 were significantly increased in the xylem ranging from the expanding xylem to the lignifying xylem, suggesting their association with wood formation. Promoter analyses revealed that most of the preferentially xylem-expressed RING-H2 genes possessed SNBE, TERE, M46RE, AC and SMRE cis-elements, which are involved in secondary cell wall biosynthesis and programmed cell death. Based on the promoter GUS-based analysis result, PtrRHH94 was indicated to be associated with wood formation in transgenic $P$. trichocarpa. Taken together, dozens of Populus RING-H2 gene candidates associated with wood formation have been identified based on multiple gene expression analyses.
\end{abstract}

Keywords: Populus trichocarpa; RING-H2 gene; wood formation; gene expression; secondary cell wall (SCW); programmed cell death (PCD)

\section{Introduction}

Wood is used industrially as timber for construction, pulp for paper manufacturing and a renewable source for bioenergy. The extensive use of wood demands greater understanding of the molecular basis of wood formation to improve artificial tree breeding. Wood formation is a complex developmental process undergoing cambial cell proliferation, xylem cell specification and expansion, secondary cell wall (SCW) biosynthesis and programmed cell death (PCD) [1,2]. Great progress has been made in the understanding of vascular cambium activity, xylem cell differentiation and expansion [3-5]. Most biosynthetic enzymes for wood components (cellulose, xylan and lignin) have been identified, and a number of them have been functionally characterized [5-11]. In recent decades, some vital transcription factors (TFs) have been identified to function in SCW biosynthesis, and several regulating networks have been constructed in these TFs [12-14]. After deposition of secondary walls, fibers and vessels (angiosperm) undergo PCD in wood, and some genes (for instance, encoding proteases, nucleases and autophage-related proteins) have displayed the potential roles in regulating PCD during wood formation $[15,16]$. Although the delightful understandings of molecular basis on wood formation have been acquired, the potential genes and proteins involved in this complex developmental process remain to be identified.

The RING genes are a super gene family, whose proteins have the characteristic of the conserved cysteines and histidines (Cys-X2-Cys-X9-39-Cys-X1-3-His-X2-3-Cys/His- 
X2-Cys-X4-48-Cys-X2-Cys, where X can be substituted by any amino acid), binding two zinc ions in a cross-brace structure $[17,18]$. Two canonical RING domain proteins, RING-HC (C3HC4) and RING-H2 (C3H2C3), were distinguished from the existence of either a Cys or His residue at the metal ligand position five [19-21] and the modified RING types, such as RING-v, RING-D, RING-G or RING-S/T, also have been identified in several species. The majority of Arabidopsis canonical and modified RING domain proteins were active in vitro ubiquitination assays, and they were proposed as ubiquitin ligase E3, participating in the ubiquitin proteasome system [22]. During wood formation, fibers and vessels undergo PCD and the rupture of tonoplasts leads to the release of digestive enzymes, degrading cell components in fibers and vessels $[2,16]$. The suppression of proteasomes has perturbed PCD of vessels in poplar and Arabidopsis [23,24]. Whether the RING genes are involved in wood formation remains to be identified in trees.

The RING-H2 gene family, the most abundant RING-type, possesses 241 members in Arabidopsis, 281 in rice and 367 in apple [25-27], suggesting they are involved in a variety of biological processes. A set of RING-H2 proteins have been reported to play a role in stress-related responses such as water, salt and pathogen stresses [28-35]. For instance, overexpression of OsSDIR1, a RING-H2 gene, significantly improved drought tolerance in transgenic rice [30]. Several RING-H2 genes participated in hormone biosynthesis and signal transduction, as well as photomorphogenesis with light signaling and responses [36-42]. In addition, the RING proteins also participated in metabolism, nodule formation and gravitropism [43]. For instance, the wavy growth 3, a RING-H2 protein, controlled the gravitropic response in Arabidopsis roots [44]. Arabidopsis DELLA proteins, negatively regulating ethylene signal transduction, were ubiquitinated for degradation by the RING protein complex [45]. Recently, PtaRHE1, a RING-H2 protein in Populus tremula $\times$ Populus alba, was reported to be involved in secondary phloem fiber formation [46-48]. To date, except for PtaRHE1, little is known about the function of RING-H2 genes in wood formation in trees.

The objective of this study was to identify RING-H2 gene candidates related to wood formation in poplar. We identified 288 RING-H2 genes in Populus trichocarpa (Torr. \& Gray), and found 64 of the RING-H2 genes were highly or preferentially expressed in stem xylem. Most of the preferentially xylem-expressed RING-H2 genes possessed SNBE, TERE, M46RE, AC and SMRE cis-elements involved in SCW and PCD. The PtrRHH94 promoter GUS-based analysis determined its association with wood formation in transgenic $P$. trichocarpa.

\section{Materials and Methods}

\subsection{Plant Materials and Growth Conditions}

Wild-type P. trichocarpa (Nisqually-1) and transgenic plants were planted in the greenhouse of Northeast Forestry University under the conditions with a long day ( $16 \mathrm{~h}$ light $/ 8 \mathrm{~h}$ dark) at $23-25^{\circ} \mathrm{C}$. The three-month-old young trees were used for analyzing the gene expression levels in different tissues and organs. Samples, including phloem, xylem, root, apical bud, young leaf, mature leaf and petiole, were collected as described in a previous study [49].

\subsection{Identification of the RING-H2 Genes in P. trichocarpa}

We exploited two search methods to identify the RING gene family in the genome of $P$. trichocarpa as follows: (1) Pfam RING domain (PF00097) was utilized as queries to search against the whole genome with the BLAST tools [50]; (2) amino acid sequences of 469 retrieved RING proteins in Arabidopsis were employed as queries to search one after another against the whole Populus genome using the Phytozome database. The protein sequences, genomic sequences and coding sequences (CDS) of $P$. trichocarpa RING genes were downloaded from the Phytozome v12.1 (https://phytozome.jgi.doe.gov/pz/portal.html). All objective proteins were analyzed manually using the SMART database to identify the presence of the RING domain [51]. 


\subsection{Phylogenetic and Chromosomal Duplication Analyses}

Multiple sequence alignments of the full-length RING proteins and RING domains were performed using the ClustalX (Version 2.1) program with default parameters [52]. The unrooted phylogenetic trees were constructed with MEGA (Version 6.0) using the neighbor-joining (NJ) method with 1000 bootstrap replicates [53].

Chromosomal location data of 282 RING-H2 genes were obtained from the Phytozome v12.1. Except for six RING-H2 genes in unattributed scaffolds, the rest were marked on the chromosomes using MapChart software [54]. The Populus genome has undergone at least three large-scaled genome-wide duplications [55]. The tandem gene pairs and segmental duplication genes were labeled according to the previously reported standard with a distance less than $9 \mathrm{~kb}$ on duplication blocks and high protein sequence similarities (>80\%) [56], and connected by colored solid line. Gene structures including the exon and intron organization were generated with Gene Structure Display Server [57]. Conserved motifs of the RING-H2 proteins were analyzed using the SMART tools [51].

\subsection{Microarray and AspWood RNAseq Analyses}

Genome-wide Affymetrix expression data were normalized by General Comprehensive Operating System (GCOS) method, with a target (TGT) value of 500, which were received at the NetAffx Analysis Center (http://www.affymetrix.com/) under the accession number GSE13990 (expression data for various Populus balsamifera tissues). The probe sets of RING-H2 genes were obtained by an online Probe Matchtool at the NetAffx Analysis Center (https://www.affymetrix.com/site/login). The expression values of 249 RING-H2 genes with more than one probe sets were averaged and several genes that had the same probe set were considered to have the same transcriptional levels. Heatmaps of RING-H2 genes in microarray data were analyzed using Heat Map Illustrator (HemI) with the default settings [58]. In addition, 64 RING-H2 genes highly or preferentially expressed in xylem were analyzed on transcriptional levels using AspWood RNAseq dataset (http://aspwood.popgenie.org/aspwood-v3.0).

\section{5. qRT-PCR Analysis}

Total RNAs were extracted from all samples using pBIOZOL (Bio-Flux, Beijing, China) in accordance with the manufacturer's protocols. The prepared RNAs were reversely transcribed to cDNAs using the PrimeScript RT Reagent Kit with gDNA Eraser (TaKaRa, Dalian, China). The qRT-PCR experiments were performed with SYBR Green (TaKaRa, Dalian, China) in an ABI 7500 system. The reaction mixture $(20 \mu \mathrm{L})$ consisted of $10 \mu \mathrm{L}$ of $2 \times$ TB Green Premix Ex Taq II, $0.4 \mu \mathrm{L}$ of ROX Reference Dye II, $7 \mu \mathrm{L}$ of distilled $\mathrm{H}_{2} \mathrm{O}, 1 \mu \mathrm{L}$ of cDNA template and $0.8 \mu \mathrm{L}$ of each gene-specific primer. The PCR parameters were as follows: $95^{\circ} \mathrm{C}$ for $30 \mathrm{~s} ; 40$ cycles of $95^{\circ} \mathrm{C}$ for $5 \mathrm{~s}, 58^{\circ} \mathrm{C}$ for $15 \mathrm{~s}, 72{ }^{\circ} \mathrm{C}$ for $30 \mathrm{~s}$. PtrActin 2 was used as the internal control and the comparative cycle threshold $\left(\mathrm{Ct}, 2^{-\Delta \mathrm{Ct}}\right)$ method was used to calculate gene expression levels. Three technical replicates were done for each sample.

\subsection{Identification of Xylem Development-Related Cis-Elements in the Promoters}

The $3 \mathrm{~kb}$ promoter sequences (upstream DNA sequence of the $5^{\prime}$-UTR) of the RING-H2 genes were searched for xylem development-related cis-elements by manual analysis. A total of 11 cis-elements were identified including SNBE (WNNYBTNNNNNNNAMGNHW), TERE (CTTNAAAGCNA), M46RE (RKTWGGTR), ACI (ACCTACC), ACII (ACCAACC), ACIII (ACCTAAC), SMRE1 (ACCAAAT), SMRE2 (ACCAACT), SMRE3 (ACCAAAC), SMRE5 (ACCTAAT) and SMRE6 (ACCTACT). The detailed positions and patterns of these cis-elements in the promoter regions were shown with the help of the DOG 1.0 software [59].

\subsection{Plasmid Construction and Agrobacterium-Mediated Transformation}

The P. trichocarpa genomic DNA was extracted from the leaves using a plant genomic DNA extraction kit (Bioteke, Beijing, China). With this genomic DNA as template, approximately $3 \mathrm{~kb}$ 
promoter regions of PtrRHH94 were amplified by PCR, and inserted into the vector $\mathrm{pENTR/D-TOPO}$ (Invitrogen, Carlsbad, CA, USA). After DNA sequencing, the PtrRHH94 promoter fragments from the entry clone were constructed into the binary vector pGWB3 by the Gateway LR Clonase II enzyme (Invitrogen, Carlsbad, CA, USA). The construct was transformed into Agrobacterium tumefaciens strain GV3101 and subsequently transformed into P. trichocarpa as described in our previous study [60].

\subsection{Histochemical GUS Assay}

The three-month-old young trees in the greenhouse and three-week-old tissue-cultured plantlets of PtrRHH94pro::GUS transgenic lines were used for GUS staining analysis, respectively. Various tissues were incubated overnight in a GUS staining solution $\left(0.1 \mathrm{M} \mathrm{Na}_{3} \mathrm{PO}_{4}\right.$ buffer, $\mathrm{pH} 7.0,10 \mathrm{mM}$ EDTA, $2 \mathrm{mM} \mathrm{K}_{3}\left[\mathrm{Fe}(\mathrm{CN})_{6}\right], 2 \mathrm{mM} \mathrm{K}_{4}\left[\mathrm{Fe}(\mathrm{CN})_{6}\right], 1 \mathrm{mM} \mathrm{X-Gluc}$, and $0.1 \%(v / v)$ Triton X-100) at $37^{\circ} \mathrm{C}$ [61]. After the GUS signal was developed, the chlorophylls of each sample were eliminated by $70 \%(v / v)$ ethanol. Sections of samples including internodes (INs), petioles, main veins and roots were examined and photographed under a BX43 stereomicroscope (Olympus, Tokyo, Japan).

\section{Results}

\subsection{Identification of the RING-H2 Genes in P. trichocarpa}

In order to identify the RING-H2 gene family of P. trichocarpa, we search the P. trichocarpa genome with two methods: (1) the Pfam RING domain (PF00097) was used as a query to search against the whole genome with the BLAST tool; (2) the amino acid sequences of 469 retrieved Arabidopsis RING proteins were employed as queries to search one after another against the whole genome. All candidate proteins were analyzed manually using the SMART database to identify the presence of RING domains. As a result, a total of 540 RING genes were identified in the P. trichocarpa genome.

Based on the characteristic of the RING-type ubiquitin ligases [27], the 540 P. trichocarpa RING proteins were grouped into three types: RING-H2 (288), RING-HC (183) and RING-v (69), which were suggested by evolutionary relationships of the RING domains from the 540 RING proteins (Figure 1, Table S1). Of the three types, RING-H2 was the biggest family, in which the number of members was close to that of Arabidopsis and rice (241 and 281) [26,27]. All identified 288 RING-H2 genes were named as PtrRHH1 to PtrRHH288 according to the successive order of genes on the chromosomes (Figure S1). The length of proteins encoded by these RING-H2 genes varied from 81 to 1363 amino acids, the average of which was 339 amino acids (Table S2).

\subsection{Gene Duplications, Gene Structures and Conserved Motifs in Populus RING-H2 Genes}

Of the 288 RING-H2 genes, 282 were mapped by MapChart software onto the 19 chromosomes (Chrs), and the other six were localized in the scaffolds with the unattributed genomic sequence (Figure 2, Table S2). The distribution of the RING-H2 genes on the Chrs was considerable and uneven. Chr I harbored 39 RING-H2 genes, while Chr IV contained the minimum number (five genes). Gene expansion in a family depends on genome-wide duplications accompanied by segmental and tandem duplication events. The RING-H2 gene family contained 103 duplicate gene pairs, in which some reciprocal duplicate gene groups were found, such as group PtrRHH54/55/56/58, PtrRHH65/66/67/68 and PtrRHH221/223/224/227 (Figure 2), suggesting that these genes might derive from a common ancestor. In addition, five groups of RING-H2 genes (PtrRHH88/89, PtrRHH134/135/136, PtrRHH177/178, PtrRHH187/188/189/190 and PtrRHH263/264) were identified as tandem duplicates in P. trichocarpa. Approximately $18 \%$ (61/288) of the RING-H2 genes were located outside of the duplicated blocks. 


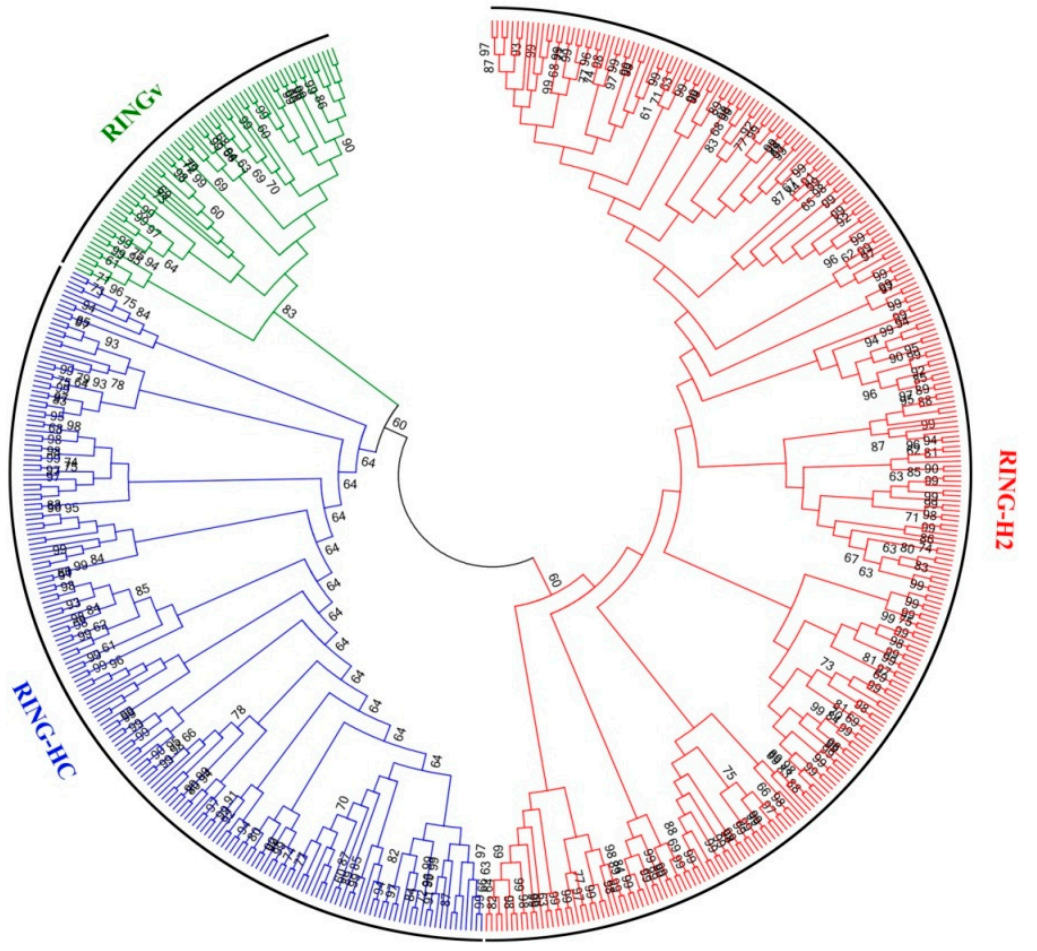

Figure 1. Phylogenetic relationship of the RING domains from 540 RING proteins in Populus trichocarpa. A phylogenic tree was constructed by MEGA 6.06 using the neighbor-joining method with 1000 bootstrap replicates. The red, blue and green represented RING-H2, RING-HC and RINGv, respectively.

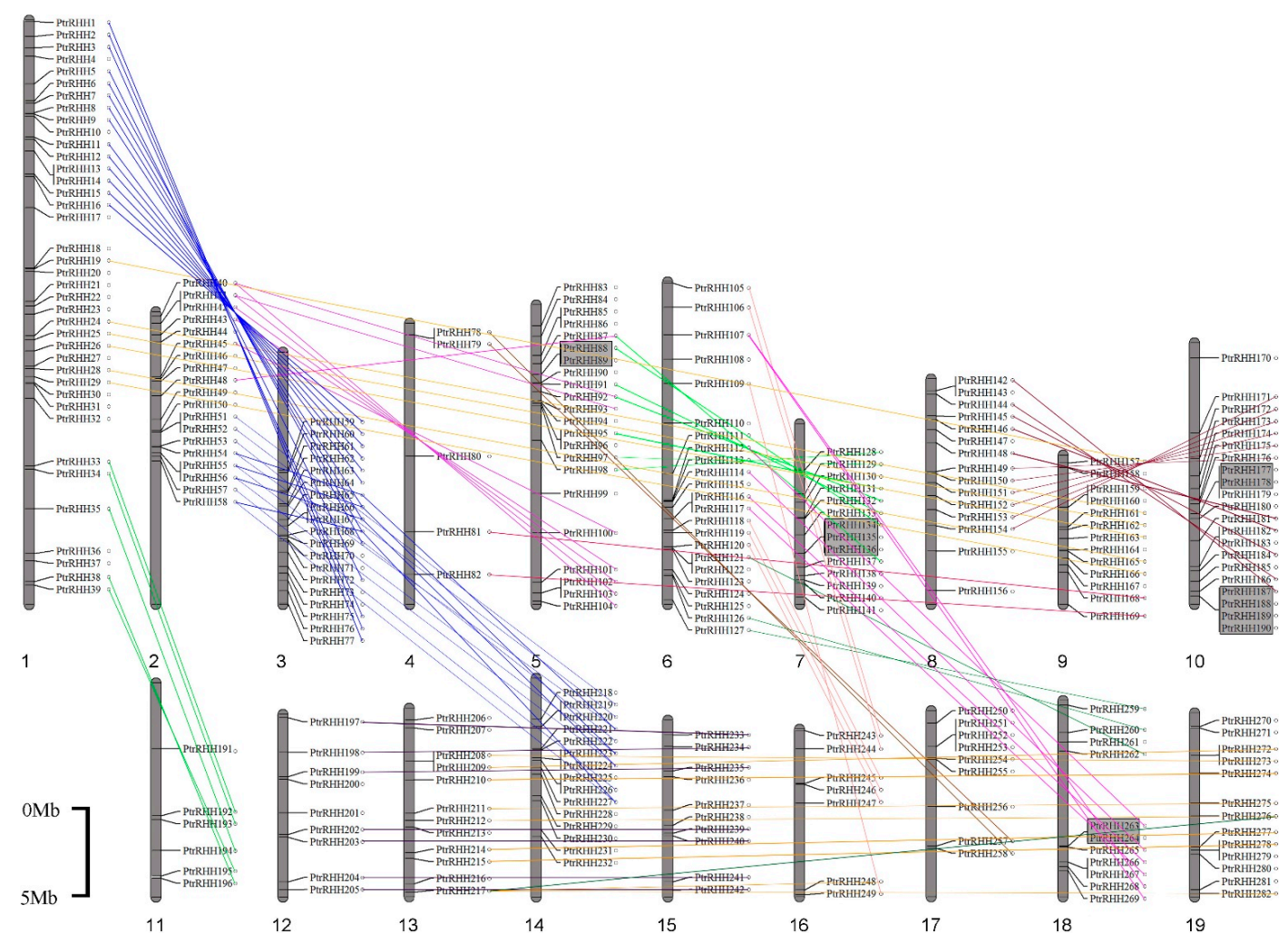

Figure 2. Gene duplications of 282 RING-H2 genes on 19 chromosomes of $P$. trichocarpa. The tandem gene pairs were labeled by small grey boxes. The segmental duplication genes were connected by color solid lines. The scale displayed a $5.0 \mathrm{Mb}$ chromosome distance. 
We compared the exon/intron organization of each RING-H2 gene, accompanied by their phylogenetic tree (Figure S2). Most RING-H2 genes in the same group possessed similar gene structure either in intron number or in exon length, whereas the members in different groups displayed diverse structural features. The conserved motif analysis showed that all the 288 RING-H2 members possessed one RING finger motif, and approximately half of the members contained one to six transmembrane domains (Figure S2). Except these, few specific motifs could be found in the RING-H2 gene family and only WD40, RWD, VWA, CUE, CLH and ZnF UBP domains existed in 18 RING-H2 members (Figure S2), suggesting functional divergence of the RING-H2 genes in P. trichocarpa.

\subsection{Identification of the RING-H2 Genes Highly or Preferentially Expressed in Populus Xylem}

To seek for the Populus RING-H2 genes associated with wood formation, we analyzed expression patterns of the RING-H2 genes in various tissues and organs (including mature leaf, female catkin, young leaf, male catkin, xylem and root) using Affymetrix poplar genome arrays [62]. Except for 39 RING-H2 genes without the relevant probe sets in the microarray dataset, we obtained the expression profiles of 249 RING-H2 genes and some RING-H2 genes displayed tissue-specific expression patterns (Figure 3a, Table S3). Of the 249 RING-H2 genes, 64 were highly or preferentially expressed in xylem and a majority of the RING-H2 genes showed low expression levels in mature leaf.

To further identify whether these 64 RING-H2 genes are related to wood formation, their transcription levels were analyzed using AspWood RNAseq dataset, which showed 28,294 gene expression profiles across the developing phloem, vascular cambium and wood forming tissues (expanding xylem cells, SCW forming xylem and maturing xylem) [63]. As illustrated in Figure 3b, the transcription levels of PtrRHH21, 33, 48, 69, 88, 93, 94, 121, 141, 166, 175, 192, 208, 214, 250 and 257 were significantly increased in the xylem ranging from the expanding xylem (T1-08 to 10) to the lignifying xylem (T1-12 to ), suggesting their association with wood formation. The transcription levels of PtrRHH67, 148, 150, 158, 219 and 259 were gradually increased in the PCD undergoing xylem (T1-15 to 24), suggesting possible involvement of these RING-H2 genes in PCD of wood formation.

Based on high and preferential expression abundances from the above microarray data and AspWood RNAseq dataset, the 30 RING-H2 genes associated with wood formation were examined by qRT-PCR on transcription levels in phloem, xylem, root, apical bud, young leaf, mature leaf and petiole (Figure 4). The results showed that most RING-H2 genes tested, such as PtrRHH33, 94 and 175, were more preferentially expressed in xylem, which was consistent with the microarray data (Table S4). Whereas, the expression levels of several RING-H2 genes (for instance, PtrRHH11 PtrRHH93 and PtrRHH144) were not higher in xylem than in other tissues, possibly owing to deviation from the microarray data.

3.4. Analysis of Xylem Development-Related Cis-Elements in the Promoter Regions of Highly or Preferentially Xylem-Expressed RING-H2 Genes

In previous studies, SNBE, TERE, M46RE, AC and SMRE, etc. had been identified as crucial cis-elements that are involved in Arabidopsis SCW biosynthesis and modification, as well as PCD [64-68]. To further evaluate their associations with wood formation, these cis-elements in the promoter regions of the highly or preferentially xylem-expressed RING-H2 genes were analyzed (Figure 5, Table S5). The results showed that the SNBE cis-element was found in the promoter regions of 23 RING-H2 genes. In addition, 12 RING-H2 genes possessed the SMRE3 cis-element in their promoter regions, and the TERE cis-element existed in six genes. The other xylem development-related cis-elements, such as M46RE, ACI, ACII, ACIII, SMRE1, SMRE2, SMRE5 and SMRE6, were also found in some RING-H2 genes. Considering that a transcriptional network for Arabidopsis xylem might incompletely be the same as poplar, we further analyzed the number of xylem development-related cis-elements in the promoters of 20 RING-H2 genes that were not expressed in xylem from the above microarray data. As a result, the 20 RING-H2 genes contained no or few xylem development-related cis-elements (Table S6). Taken together, our findings indicated that these highly or preferentially xylem-expressed RING-H2 genes possess multiple cis-elements related to xylem development, suggesting their participation in wood formation. 

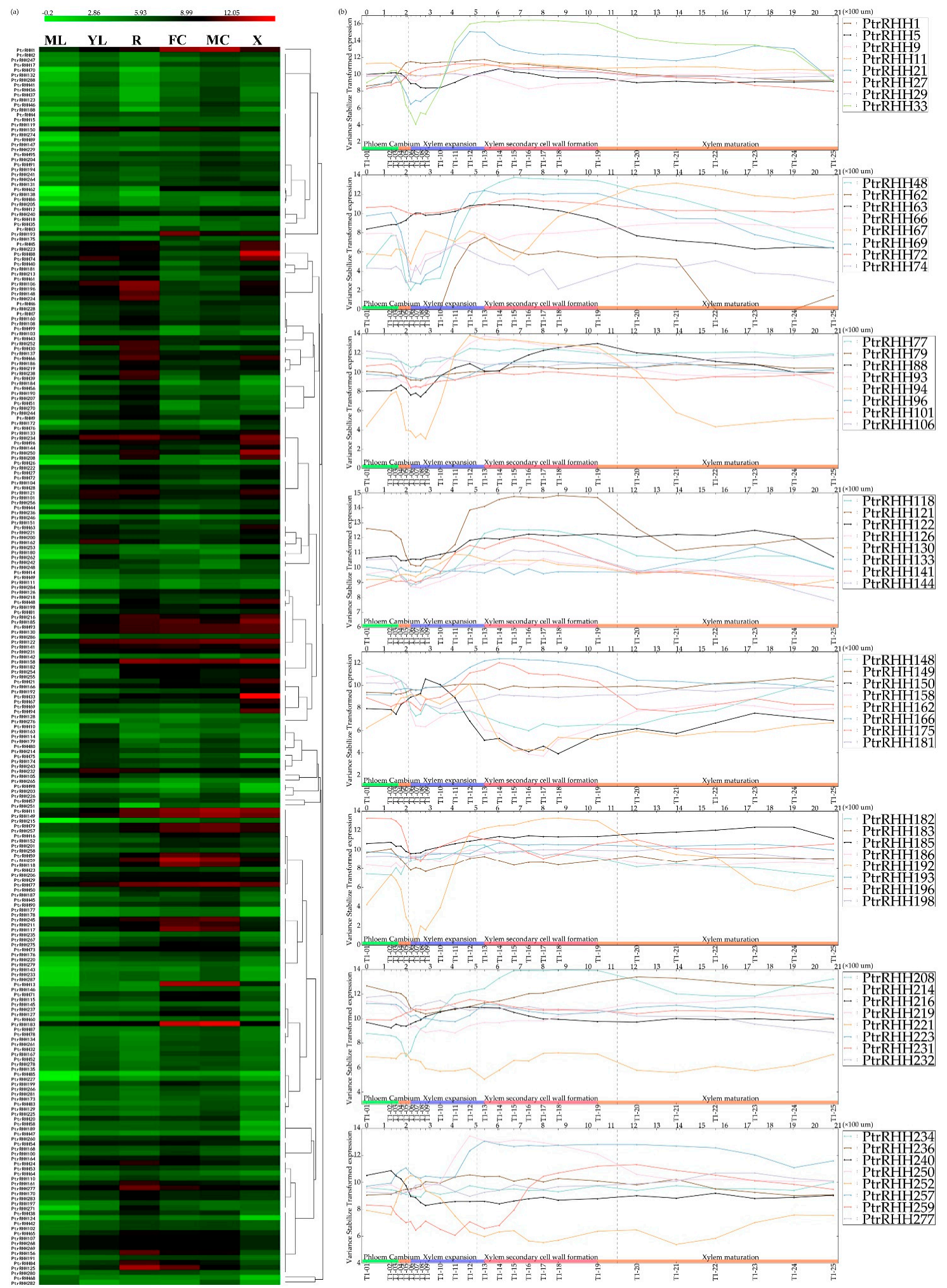

Figure 3. The expression profiles of poplar RING-H2 genes in different tissues and during wood formation. (a) Expressions of RING-H2 genes were extracted from Affymetrix expression data (GSE13990) at the NetAffx Analysis Center (http://www.affymetrix.com). ML, mature leaf; FC, female catkin; YL, young leaf; MC, male catkin; X, xylem; R, root. (b) Sixty-four RING-H2 genes highly or preferentially expressed in xylem were analyzed using AspWood RNAseq dataset (http: //aspwood.popgenie.org/aspwood-v3.0) during wood formation. Different color lines represent different genes. 


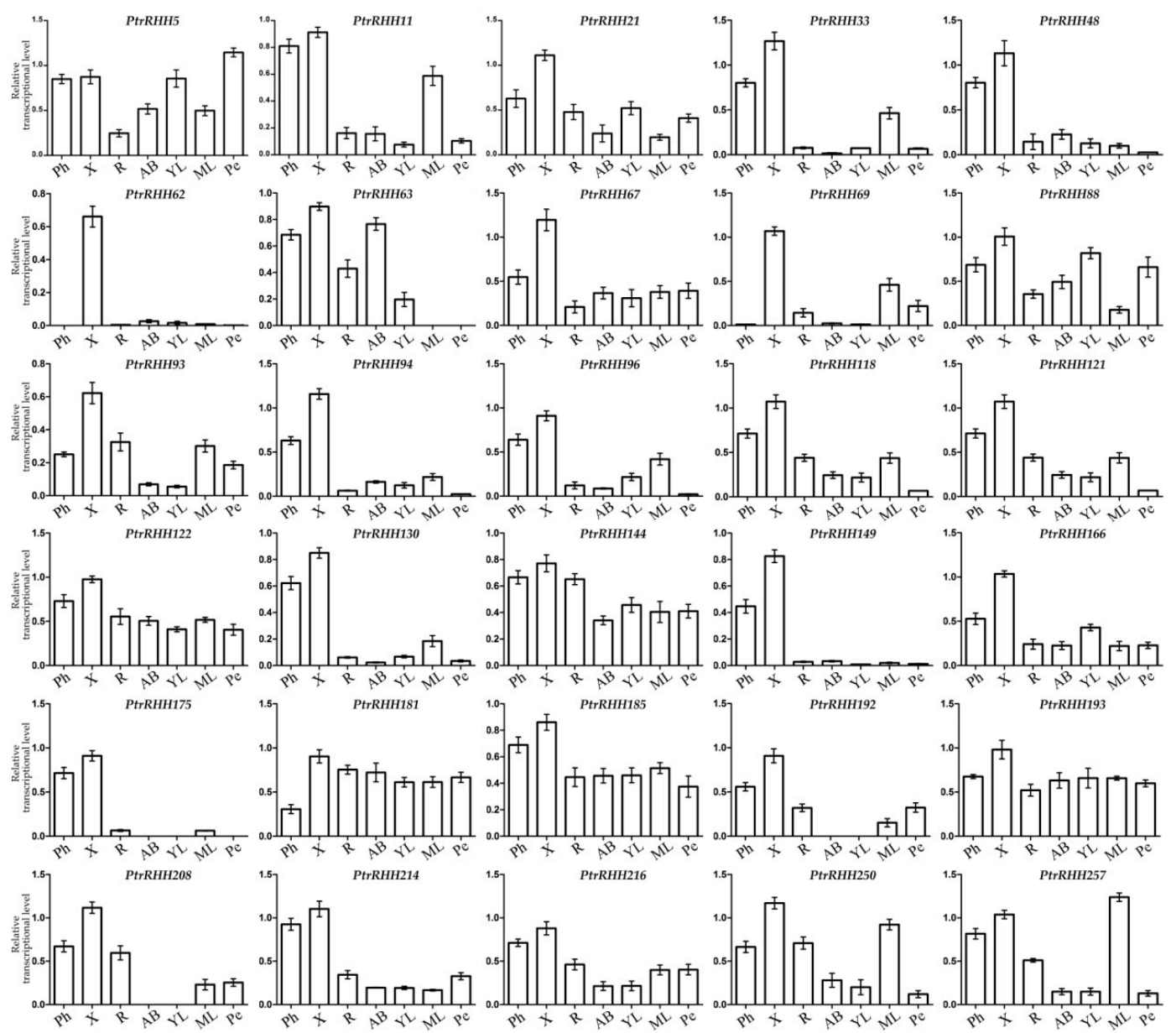

Figure 4. Transcription levels of 30 RING-H2 genes in various tissues of three-month-old young trees using qRT-PCR analysis. The PtrActin 2 gene was used as control. Ph, phloem; X, xylem; R, root; AB, apical bud; YL, young leaf; ML, mature leaf; Pe, petiole.

\subsection{Promoter: GUS-Based Analysis of PtrRHH94 Related to Wood Formation in Transgenic Populus}

The activity of the PtrRHH94 promoter in various tissues was determined to reveal whether it associates with wood formation. The PtrRHH94 promoter region was isolated, and a PtrRHH94pro::GUS binary expression vector was constructed. After transformation into wild-type $P$. trichocarpa, we generated PtrRHH94pro::GUS transgenic young trees that expressed a GUS gene driven by PtrRHH94 promoter. A GUS staining signal was not observed in the two-week-old transgenic plantlets on woody plant media (WPM), whereas stem IN5 segments with secondary xylem presented GUS activity in one-month-old transgenic plantlets (Figure 6a-d). For three-month-old transgenic young trees grown in the greenhouse, a GUS staining signal was not detected in the apical bud, mature leaf and petiole, but in the main leaf vein (Figure 6e-h). However, strong a GUS staining signal was visible in the xylem of stem and root (Figure 6i-1), which are mainly secondary vascular tissues (woods) of the trees. 


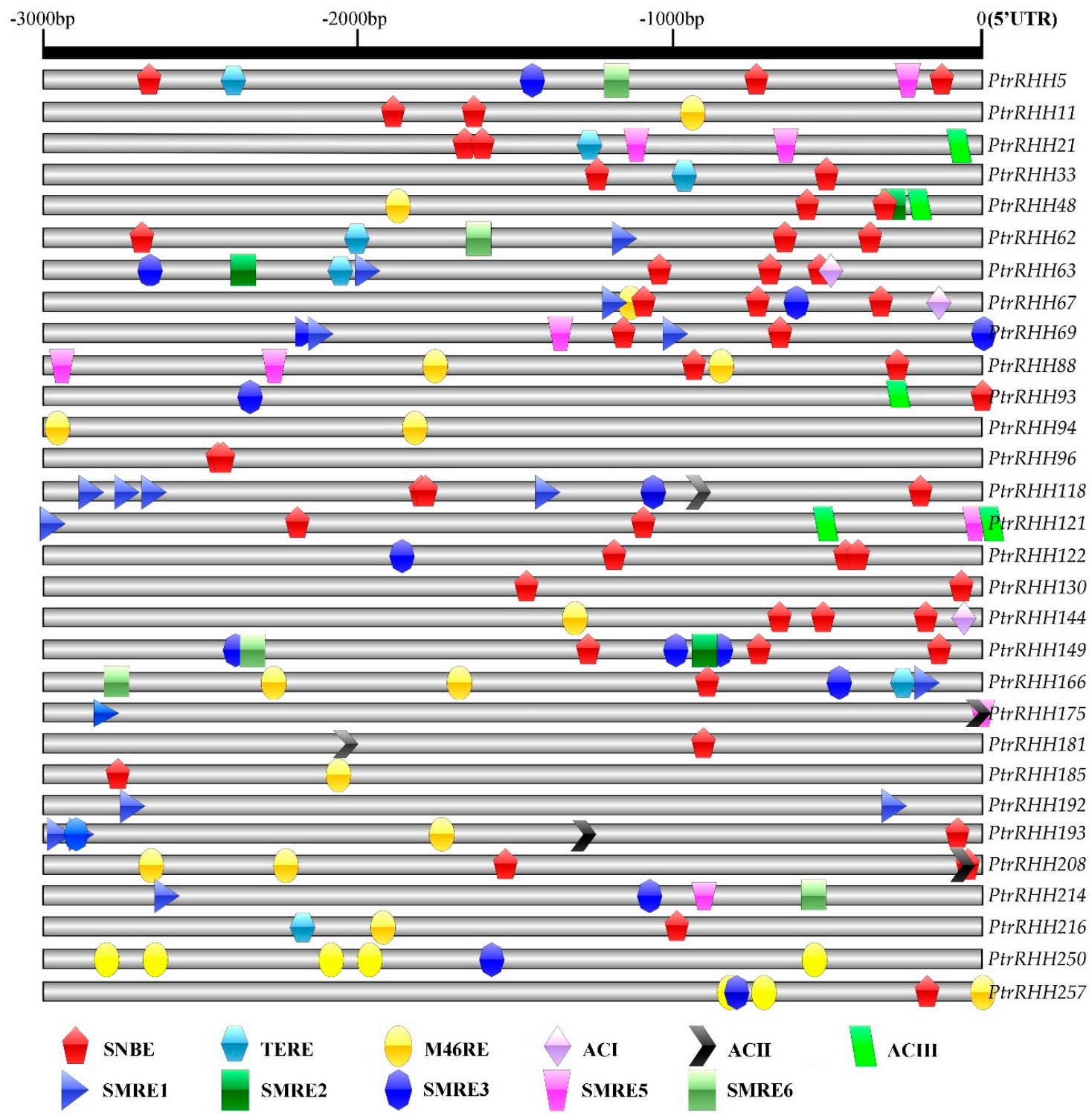

Figure 5. Xylem development-related cis-elements in the promoter regions of the RING-H2 genes highly or preferentially expressed in xylem. Different cis-elements were exhibited by different shapes with different colors.

We further examined GUS staining signals in IN1, IN3, IN5, IN7 and IN9 segments of the developing stem from three-month-old PtrRHH94pro::GUS transgenic trees. There was no GUS staining signals in the stem IN1 and IN3 segments, which are predominantly developing primary vascular tissues (Figure 7a,e). A developing early stem provides a developmental gradient of the lignification from apex to below. Apparently, gradual increase of GUS staining signals emerged in the stem IN5, IN7 and IN9 segments tested (Figure 7b-d), suggesting that PtrRHH94 is associated with stem lignification. Specific to cell types of the lignified stem, strong GUS staining was shown in the secondary xylem fibers and phloem fibers (Figure 7f-h), implying that PtrRHH94 may be involved in stem fiber maturity during wood formation. 
(a)
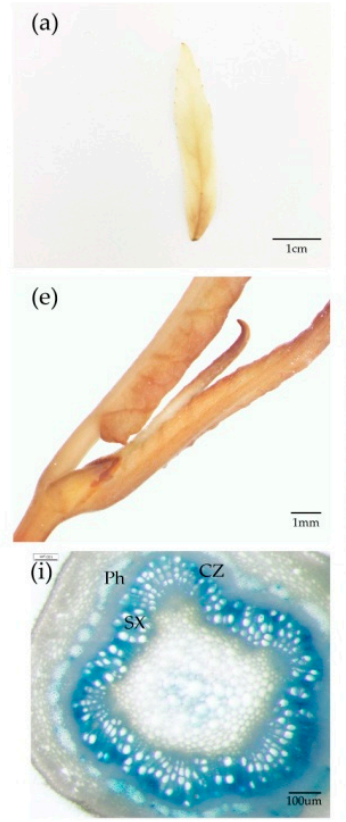

(b)
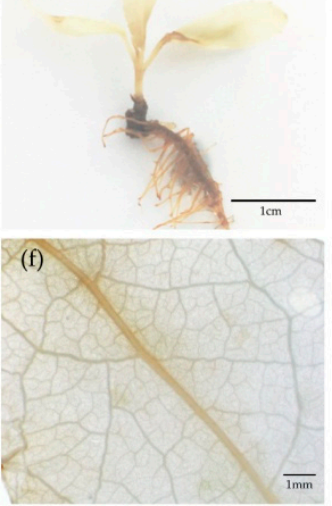

(j)

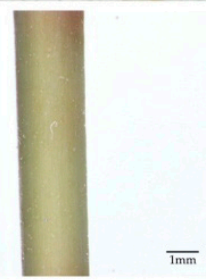

(c)

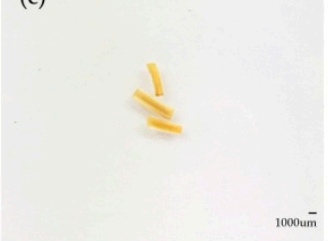

(g)

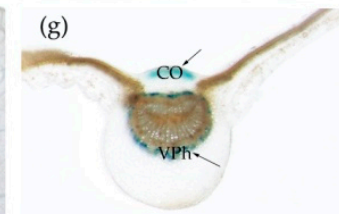

200um

(k)

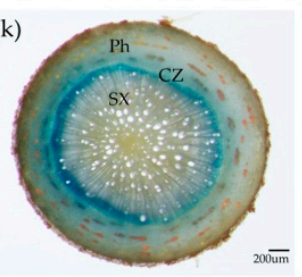

(d)

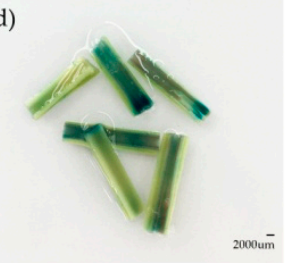

(h)

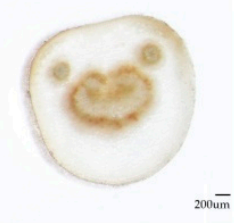

(l)

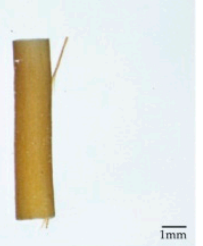

Figure 6. Histochemical GUS assays in various tissues of PtrRHH94pro::GUS transgenic P. trichocarpa. $(\mathbf{a}, \mathbf{b})$ two-week-old transgenic plantlets on woody plant media (WPM) and its young leaf. (c,d) stem internodes (INs) two and five of one-month-old transgenic plantlets on WPM media. $(\mathbf{e}, \mathbf{f}, \mathbf{j}, \mathbf{l})$ apical bud, mature leaf, stem IN6 and root of three-month-old transgenic young trees in the greenhouse. $(\mathrm{g}-\mathbf{i}, \mathbf{k})$ cross-sections of main vein and petiole of the eighth leaf, stem IN6 and root from three-month-old transgenic young trees. CO, collenchymas; VPh, vein of phloem; Ph, phloem; CZ, cambial zone; SX, secondary xylem.

IN3

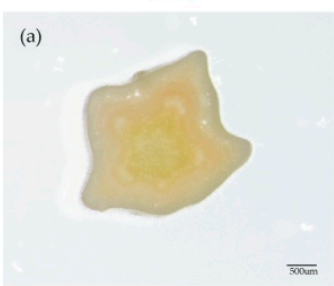

(e)

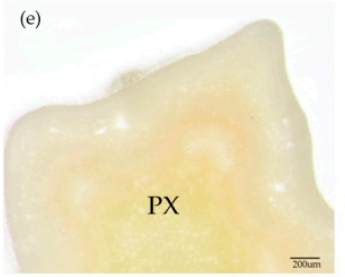

IN5
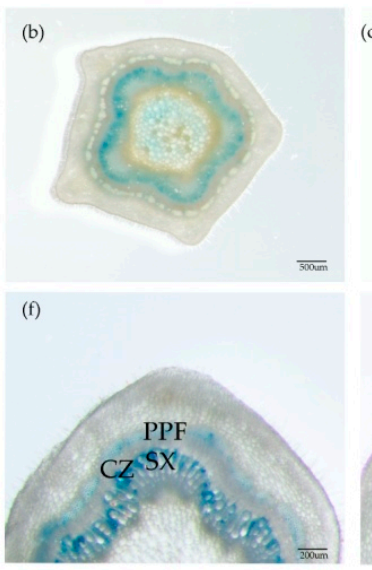

IN7

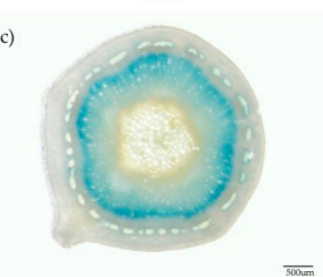

(g)

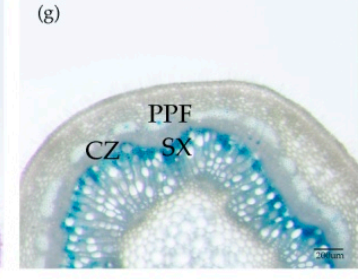

IN9

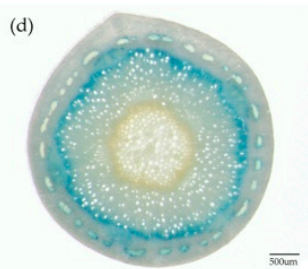

(h)

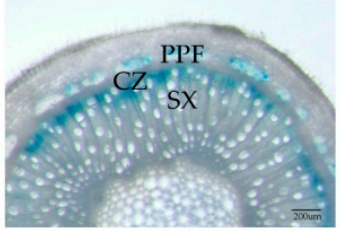

Figure 7. Histochemical GUS assay in the developing stems of PtrRHH94pro::GUS transgenic young trees. (a-d) Cross-sections of the internodes (INs) 3, 5, 7 and 9; (e-h) the magnified cross-sections of the INs 3, 5, 7 and 9. PX, primary xylem; PPF, primary phloem fiber; CZ, cambial zone; SX, secondary xylem.

\section{Discussion}

The RING-H2 genes, which generally encode E3 ligases, have been reported to participate in various biological processes, such as stress responses, hormone biosynthesis, signal transduction and photomorphogenesis in herbaceous plants $[33,69,70]$. However, the study to investigate whether the RING genes are associated with wood formation is lacking. In the present study, we have performed an overall identification of the RING-H2 genes in P. trichocarpa, which includes identification of gene family, analysis of gene expansion, determination of the xylem-preferentially expressed RING-H2 
genes, analyses of the xylem development-related cis-elements and assay of PtrRHH94 promoter activity in the developing woods. Consequently, more than a dozen of PtrRHHs (PtrRHH33, 48, 94, 175 and 208, etc.) were proposed to be involved in wood formation in P. trichocarpa.

A previous study reported 91 RING-HC genes in P. trichocarpa [71]. In this study, we have identified 540 RING genes in P. trichocarpa, which were classified into three types, namely RING-H2 (288), RING-HC (183) and RING-v (69). As the largest type of the RING gene superfamily, the number of P. trichocarpa RING-H2 genes is close to that of Arabidopsis (241) and rice (281) and less than that of apple (367) [25-27]. The P. trichocarpa genome has undergone at least three large-scaled genome-wide duplications [55], which greatly contributes to gene expansion in the family. The RING-H2 gene family in the P. trichocarpa genome contained 103 duplicate gene pairs (Figure 2), supporting this idea. Nevertheless, $P$. trichocarpa RING-H2 gene family members do not meet our expectations, because the RING-H2 domain was lost in these duplicated genes with partial and incomplete coding sequences. The phylogenetic tree displayed no obvious large clade of $P$. trichocarpa RING-H2 genes (Figure 1), possibly because of profound changes in these RING protein sequences during evolution, except for the RING-H2 domain.

In P. trichocarpa, the RING-H2 genes have diversified expression patterns, which were suggested by microarray data (Figure 3a). The objective of this study was to identify the RING-H2 genes that are related to wood formation. A total of 64 RING-H2 genes have shown high or preferential expression levels in xylem of $P$. trichocarpa, and most of them have been determined using qRT-PCR analysis (Figures $3 \mathrm{a}$ and 4). Among them, more than 10 RING-H2 genes have displayed positive correlation of their transcript levels with the development of wood forming tissues, including the expanding, lignifying and PCD undergoing xylem based on AspWood RNAseq dataset (Figure 3b). Taken together, these expression data indicate that the RING-H2 genes should function in or associate with wood formation.

For this objective, we have filtered the SCW-related cis-elements in the promoter regions of the highly or preferentially xylem-expressed RING-H2 genes, and 23 of the 30 tested have the SNBE cis-elements (Figure 5). During SCW biosynthesis, NAC secondary wall master switches bind several cis-elements $[64,65]$, such as SNBE and TERE, to activate their downstream gene transcription. Arabidopsis At5g55970 (encoding a RING-H2 protein) was regulated by Zinnia ZCP4, a cysteine protease functioning in PCD during tracheary element (TE) differentiation and proposed as a TE differentiation-related gene with the TERE-like cis-elements [65]. PtrRHH33 (Potri.001G371200), as the homolog of At5g55970 in P. trichocarpa, contained three TERE-like cis-elements, implying its role in PCD of wood formation. MYB secondary wall mast switches recognize M46RE, SMRE and AC cis-elements, and activate the downstream genes that are associated with SCW biosynthesis and PCD $[2,65,67,68]$. Of the 30 poplar RING-H2 genes tested, 13 possessed the M46RE cis-element in their promoter regions, and PtrRHH250 (Potri.017G012600) had the largest number of the cis-element (five; Figure 5). The RING-H2 gene (At2g20650), the homolog of PtrRHH250, is a direct target of MYB46 in Arabidopsis [67]. The coordinated activation of SCW and PCD genes during wood formation is mediated by a transcription network encompassing secondary wall NAC and MYB master switches and their downstream TFs [14,72].

In this study, we have evaluated the association of PtrRHH94 with wood formation based on its promoter activity in PtrRHH94pro::GUS transgenic plants. The PtrRHH94 promoter activity predominantly appears in the lignified stem and root, and its intensity holds pace with the increase of stem lignification (Figures 6 and 7). The PtrRHH94 intensely expresses in fibers, mainly wood fibers, which has been suggested by GUS staining signals. Thus, it is assumed that PtrRHH94 may function in the fibers during wood formation. Interestingly, the PtrRHH94 promoter contains two M46REs and no other SCW-related cis-elements (Figure 5), implying that transcription of PtrRHH94 should be directly regulated by MYB46, not by secondary wall NACs (the first-level master switches). In transcriptional regulatory network controlling SCW biosynthesis, MYB46, a direct target of secondary wall NACs, acts as a second-level master switch capable of directly activating a suite of downstream TFs and SCW 
biosynthetic genes $[67,68]$. Considering that PtrRHH94 encodes a putative ubiquitin ligase E3, it is reasonable that PtrRHH94 might play crucial role in PCD of wood formation, but we do not rule out the possibility of its participation in SCW formation.

\section{Conclusions}

We have identified 288 RING-H2 genes in P. trichocarpa. Based on multiple gene expression analyses including a microarray dataset, AspWood RNAseq dataset and qRT-PCR data, a dozen of RING-H2 gene candidates are proposed to play a role in wood formation. The SCW- and/or PCD-related cis-elements, mainly SNBE, TERE, M46RE, AC and SMRE, exist in the promoter regions of these RING-H2 genes. Promoter GUS activities in transgenic Populus have demonstrated the association of PtrRHH94 with wood formation. In addition, PtrRHH 33, 48, 94, 121, 175, 192, 208 and 250 are the most attentive RING-H2 genes related to wood formation. Next, each of these expected RING-H2 genes will be knocked out via CRISPR/Cas9-mediated gene editing technique, which will reveal its molecular mechanism in wood formation.

Supplementary Materials: The following are available online at http://www.mdpi.com/1999-4907/10/8/698/s1, Figure S1: Motif sequences alignment of 288 RING-H2 genes identified in P. trichocarpa, Figure S2: Phylogenetic relationships, gene structure and motif of Populus RING-H2 genes, Table S1: The RING domain sequences of 540 P. trichocarpa RING genes, Table S2: List of 288 RING-H2 genes identified in P. trichocarpa and their protein lengths, Table S3: Probes of Populus RING-H2 genes, Table S4: List of primers used for qRT-PCR analysis, Table S5: Xylem development-related cis-elements analyzed in the $30 \mathrm{RING-H2}$ genes, Table S6: Analysis of xylem development-related cis-elements in the promoters of 20 RING-H2 genes that are not expressed in xylem.

Author Contributions: Conceptualization, Y.C.; experiment design, X.M. and Y.C.; investigation, G.T., H.S., S.C. and W.X.; data curation, G.T., H.S., S.C. and W.X.; original draft preparation, G.T.; review and editing, X.M. and Y.C.; supervision, Y.C.; funding acquisition, Y.C.

Funding: This research was funded by Projects of the Natural Science Foundation of Heilongiiang Province (JC2016003) and the National Natural Science Foundation of China (31570580, 31770637).

Conflicts of Interest: The authors declare no conflicts of interest.

\section{References}

1. Guerriero, G.; Sergeant, K.; Hausman, J.-F. Wood biosynthesis and typologies: A molecular rhapsody. Tree Physiol. 2014, 34, 839-855. [CrossRef] [PubMed]

2. Zhang, J.; Nieminen, K.; Serra, J.A.A.; Helariutta, Y. The formation of wood and its control. Curr. Opin. Plant Biol. 2014, 17, 56-63. [CrossRef] [PubMed]

3. Baucher, M.; El Jaziri, M.; Vandeputte, O. From primary to secondary growth: Origin and development of the vascular system. J. Exp. Bot. 2007, 58, 3485-3501. [CrossRef] [PubMed]

4. Déjardin, A.; Laurans, F.; Arnaud, D.; Breton, C.; Pilate, G.; Leplé, J.C. Wood formation in Angiosperms. Comptes Rendus Biol. 2010, 333, 325-334. [CrossRef] [PubMed]

5. Ye, Z.-H.; Zhong, R. Molecular control of wood formation in trees. J. Exp. Bot. 2015, 66, 4119-4131. [CrossRef] [PubMed]

6. Mellerowicz, E.J.; Sundberg, B. Wood cell walls: Biosynthesis, developmental dynamics and their implications for wood properties. Curr. Opin. Plant Biol. 2008, 11, 293-300. [CrossRef] [PubMed]

7. Mc Farlane, H.; Döring, A.; Persson, S. The Cell Biology of Cellulose Synthesis. Annu. Rev. Plant Biol. 2014, 65, 69-94. [CrossRef] [PubMed]

8. Scheller, H.V.; Ulvskov, P. Hemicelluloses. Annu. Rev. Plant Biol. 2010, 61, 263-289. [CrossRef] [PubMed]

9. Rennie, E.A.; Scheller, H.V. Xylan biosynthesis. Curr. Opin. Biotechnol. 2014, 26, 100-107. [CrossRef] [PubMed]

10. Barros, J.; Serk, H.; Granlund, I.; Pesquet, E. The cell biology of lignification in higher plants. Ann. Bot. 2015, 115, 1053-1074. [CrossRef]

11. Zhao, Q. Lignification: Flexibility, Biosynthesis and Regulation. Trends Plant Sci. 2016, 21, 713-721. [CrossRef] [PubMed]

12. Demura, T.; Fukuda, H. Transcriptional regulation in wood formation. Trends Plant Sci. 2007, 12, 64-70. [CrossRef] [PubMed] 
13. Du, J.; Groover, A. Transcriptional Regulation of Secondary Growth and Wood Formation. J. Integr. Plant Biol. 2010, 52, 17-27. [CrossRef] [PubMed]

14. Zhong, R.; Ye, Z.H. Secondary cell walls: Biosynthesis, patterned deposition and transcriptional regulation. Plant Cell Physiol. 2015, 56, 195-214. [CrossRef] [PubMed]

15. Turner, S.; Gallois, P.; Brown, D. Tracheary element differentiation. Annu. Rev. Plant Biol. 2007, 58, 407-433. [CrossRef] [PubMed]

16. Courtois-Moreau, C.L.; Pesquet, E.; Sjödin, A.; Muñiz, L.; Bollhöner, B.; Kaneda, M.; Samuels, L.; Jansson, S.; Tuominen, H. A unique program for cell death in xylem fibers of Populus stem. Plant J. 2009, 58, 260-274. [CrossRef] [PubMed]

17. Borden, K.L. RING domains: Master builders of molecular scaffolds? J. Mol. Biol. 2000, 295, 1103-1112. [CrossRef]

18. Kosarev, P.; Mayer, K.F.X.; Hardtke, C.S. Evaluation and classification of RING-finger domains encoded by the Arabidopsis genome. Genome Biol. 2002, 3, 1-12. [CrossRef]

19. Freemont, P.S. The RING finger. A novel protein sequence motif related to the zinc finger. Ann. N. Y. Acad. Sci. 1993, 684, 174-192. [CrossRef]

20. Freemont, P.S. RING for destruction? Curr. Biol. 2000, 10, 84-87. [CrossRef]

21. Lovering, R.; Hanson, I.M.; Borden, K.L.; Martin, S.; O’Reilly, N.J.; Evan, G.I.; Rahman, D.; Pappin, D.J.; Trowsdale, J.; Freemont, P.S. Identification and preliminary characterization of a protein motif related to the zinc finger. Proc. Natl. Acad. Sci. USA 1993, 90, 2112-2116. [CrossRef] [PubMed]

22. Ramadan, A.; Nemoto, K.; Seki, M.; Shinozaki, K.; Takeda, H.; Takahashi, H.; Sawasaki, T. Wheat germ-based protein libraries for the functional characterisation of the Arabidopsis E2 ubiquitin conjugating enzymes and the RING-type E3 ubiquitin ligase enzymes. BMC Plant Biol. 2015, 15, 275. [CrossRef] [PubMed]

23. Han, J.-J.; Lin, W.; Oda, Y.; Cui, K.-M.; Fukuda, H.; He, X.-Q. The proteasome is responsible for caspase-3-like activity during xylem development. Plant J. 2012, 72, 129-141. [CrossRef] [PubMed]

24. Fukuda, H. Xylogenesis: Initiation, progression, and cell death. Annu. Rev. Plant Biol. 1996, 47, $299-325$. [CrossRef]

25. Li, Y.; Wu, B.; Yu, Y.; Yang, G.; Wu, C.; Zheng, C. Genome-wide analysis of the RING finger gene family in apple. Mol. Genet. Genom. 2011, 286, 81-94. [CrossRef] [PubMed]

26. Lim, S.D.; Yim, W.C.; Moon, J.C.; Kim, D.S.; Lee, B.M.; Jang, C.S. A gene family encoding RING finger proteins in rice: Their expansion, expression diversity, and co-expressed genes. Plant Mol. Biol. 2010, 72, 369-380. [CrossRef]

27. Stone, S.L.; Hauksdóttir, H.; Troy, A.; Herschleb, J.; Kraft, E.; Callis, J. Functional Analysis of the RING-Type Ubiquitin Ligase Family of Arabidopsis. Plant Physiol. 2005, 137, 13-30. [CrossRef]

28. Cheng, M.C.; Hsieh, E.J.; Chen, J.H.; Chen, H.Y.; Lin, T.P. Arabidopsis RGLG2, functioning as a RING E3 ligase, interacts with AtERF53 and negatively regulates the plant drought stress response. Plant Physiol. 2012, 158, 363-375. [CrossRef]

29. Cho, S.K.; Ryu, M.Y.; Seo, D.H.; Kang, B.G.; Kim, W.T. The Arabidopsis RING E3 Ubiquitin Ligase AtAIRP2 Plays Combinatory Roles with AtAIRP1 in Abscisic Acid-Mediated Drought Stress Responses. Plant Physiol. 2011, 157, 2240-2257. [CrossRef]

30. Gao, T.; Wu, Y.; Zhang, Y.; Liu, L.; Ning, Y.; Wang, D.; Tong, H.; Chen, S.; Chu, C.; Xie, Q. OsSDIR1 overexpression greatly improves drought tolerance in transgenic rice. Plant Mol. Biol. 2011, 76, 145-156. [CrossRef]

31. Lee, H.K.; Cho, S.K.; Son, O.; Xu, Z.; Hwang, I.; Kim, W.T. Drought Stress-Induced Rma1H1, a RING Membrane-Anchor E3 Ubiquitin Ligase Homolog, Regulates Aquaporin Levels via Ubiquitination in Transgenic Arabidopsis Plants. Plant Cell 2009, 21, 622-641. [CrossRef] [PubMed]

32. Hong, J.K.; Choi, H.W.; Hwang, I.S.; Hwang, B.K. Role of a novel pathogen-induced pepper C3-H-C4 type RING-finger protein gene, CaRFP1, in disease susceptibility and osmotic stress tolerance. Plant Mol. Biol. 2007, 63, 571-588. [CrossRef] [PubMed]

33. Kim, S.J.; Ryu, M.Y.; Kim, W.T. Suppression of Arabidopsis RING-DUF1117 E3 ubiquitin ligases, AtRDUF1 and AtRDUF2, reduces tolerance to ABA-mediated drought stress. Biochem. Biophys. Res. Commun. 2012, 420, 141-147. [CrossRef] [PubMed] 
34. Seo, Y.S.; Choi, J.Y.; Kim, S.J.; Kim, E.Y.; Shin, J.S.; Kim, W.T. Constitutive expression of CaRma1H1, a hot pepper ER-localized RING E3 ubiquitin ligase, increases tolerance to drought and salt stresses in transgenic tomato plants. Plant Cell Rep. 2012, 31, 1659-1665. [CrossRef] [PubMed]

35. Xia, Z.; Liu, Q.; Wu, J.; Ding, J. ZmRFP1, the putative ortholog of SDIR1, encodes a RING-H2 E3 ubiquitin ligase and responds to drought stress in an ABA-dependent manner in maize. Gene 2012, 495, 146-153. [CrossRef] [PubMed]

36. Lyzenga, W.J.; Booth, J.K.; Stone, S.L. The Arabidopsis RING-type E3 ligase XBAT32 mediates the proteasomal degradation of the ethylene biosynthetic enzyme, 1-aminocyclopropane-1-carboxylate synthase 7. Plant J. 2012, 71, 23-34. [CrossRef]

37. Thines, B.; Katsir, L.; Melotto, M.; Niu, Y.; Mandaokar, A.; Liu, G.; Nomura, K.; He, S.Y.; Howe, G.A.; Browse, J. JAZ repressor proteins are targets of the $\mathrm{SCF}(\mathrm{COI} 1)$ complex during jasmonate signalling. Nature 2007, 448, 661-665. [CrossRef] [PubMed]

38. Guo, H.; Ecker, J.R. Plant responses to ethylene gas are mediated by SCF (EBF1/EBF2) dependent proteolysis of EIN3 transcription factor. Cell 2003, 115, 667-677. [CrossRef]

39. Pan, J.; Fujioka, S.; Peng, J.; Chen, J.; Li, G.; Chen, R. The E3 Ubiquitin Ligase SCFTIR1/AFB and Membrane Sterols Play Key Roles in Auxin Regulation of Endocytosis, Recycling, and Plasma Membrane Accumulation of the Auxin Efflux Transporter PIN2 in Arabidopsis thaliana. Plant Cell 2009, 21, 568-580. [CrossRef]

40. Christians, M.J.; Gingerich, D.J.; Hansen, M.; Binder, B.M.; Kieber, J.J.; Vierstra, R.D. The BTB ubiquitin ligases ETO1, EOL1 and EOL2 act collectively to regulate ethylene biosynthesis in Arabidopsis by controlling type-2 ACC synthase levels. Plant J. 2009, 57, 332-345. [CrossRef]

41. Roberts, D.; Pedmale, U.V.; Morrow, J.; Sachdev, S.; Lechner, E.; Tang, X.; Zheng, N.; Hannink, M.; Genschik, P.; Liscum, E. Modulation of Phototropic Responsiveness in Arabidopsis through Ubiquitination of Phototropin 1 by the CUL3-Ring E3 Ubiquitin Ligase CRL3 ${ }^{\text {NPH3 }}$. Plant Cell 2011, 23, 3627-3640. [CrossRef] [PubMed]

42. Cheng, Y.; Qin, G.; Dai, X.; Zhao, Y. NPY1, a BTB-NPH3-like protein, plays a critical role in auxin-regulated organogenesis in Arabidopsis. Proc. Natl. Acad. Sci. USA 2007, 104, 18825-18829. [CrossRef] [PubMed]

43. Chen, L.; Hellmann, H. Plant E3 Ligases: Flexible Enzymes in a Sessile World. Mol. Plant 2013, 6, $1388-1404$. [CrossRef] [PubMed]

44. Sakai, T.; Mochizuki, S.; Haga, K.; Uehara, Y.; Suzuki, A.; Harada, A.; Wada, T.; Ishiguro, S.; Okada, K. The WAVY GROWTH 3 E3 ligase family controls the gravitropic response in Arabidopsis roots. Plant J. 2012, 70, 303-314. [CrossRef] [PubMed]

45. Griffiths, J.; Murase, K.; Rieu, I.; Zentella, R.; Zhang, Z.-L.; Powers, S.J.; Gong, F.; Phillips, A.L.; Hedden, P.; Sun, T.-P.; et al. Genetic Characterization and Functional Analysis of the GID1 Gibberellin Receptors in Arabidopsis. Plant Cell 2006, 18, 3399-3414. [CrossRef] [PubMed]

46. Baldacci-Cresp, F.; Moussawi, J.; Leplé, J.-C.; Van Acker, R.; Kohler, A.; Candiracci, J.; Twyffels, L.; Spokevicius, A.V.; Bossinger, G.; Laurans, F.; et al. PtaRHE1, a Populus tremula $\times$ Populus alba RING-H2 protein of the ATL family, has a regulatory role in secondary phloem fibre development. Plant J. 2015, 82, 978-990. [CrossRef] [PubMed]

47. Moussawi, J.; Baldacci-Cresp, F.; El Jaziri, M.; Baucher, M. Does PtaRHE1, a poplar RING-H2 protein, play a role in water conduction through ABA signaling? Plant Signal. Behav. 2014, 9, 27611. [CrossRef] [PubMed]

48. Mukoko Bopopi, J.; Vandeputte, O.M.; Himanen, K.; Mol, A.; Vaessen, Q.; El Jaziri, M.; Baucher, M. Ectopic expression of PtaRHE1, encoding a poplar RING-H2 protein with E3 ligase activity, alters plant development and induces defence-related responses. J. Exp. Bot. 2010, 61, 297-310. [CrossRef] [PubMed]

49. Hai, G.H.; Jia, Z.G.; Xu, W.J.; Wang, C.; Cao, S.Q.; Liu, J.W.; Cheng, Y.X. Characterization of the Populus PtrCesA4 promoter in transgenic Populus alba $\times$ P. glandulosa. Plant Cell Tiss. Organ. Cult. 2016, 124, 495-505. [CrossRef]

50. Finn, R.D.; Mistry, J.; Tate, J.; Coggill, P.; Heger, A.; Pollington, J.E.; Gavin, O.L.; Gunasekaran, P.; Ceric, G.; Forslund, K.; et al. The Pfam protein families database. Nucleic Acids Res. 2010, 38, 211-222. [CrossRef]

51. Letunic, I.; Copley, R.R.; Schmidt, S.; Ciccarelli, F.D.; Doerks, T.; Schultz, J.; Ponting, C.P.; Bork, P. SMART 4.0: Towards genomic data integration. Nucleic Acids Res. 2004, 32, D142-D144. [CrossRef] [PubMed]

52. Chenna, R. Multiple sequence alignment with the Clustal series of programs. Nucleic Acids Res. 2003, 31, 3497-3500. [CrossRef] [PubMed]

53. Tamura, K.; Dudley, J.; Nei, M.; Kumar, S. MEGA4: Molecular Evolutionary Genetics Analysis (MEGA) Software Version 4.0. Mol. Biol. Evol. 2007, 24, 1596-1599. [CrossRef] [PubMed] 
54. Voorrips, R.E. MapChart: Software for the Graphical Presentation of Linkage Maps and QTLs. J. Hered. 2002, 93, 77-78. [CrossRef] [PubMed]

55. Tuskan, G.A.; DiFazio, S.; Jansson, S.; Bohlmann, J.; Grigoriev, I.; Hellsten, U.; Putnam, N.; Ralph, S.; Rombauts, S.; Salamov, A.; et al. The genome of black cottonwood, Populus trichocarpa. Science 2006, 313, 1596-1604. [CrossRef] [PubMed]

56. Lan, T.; Yang, Z.-L.; Yang, X.; Liu, Y.-J.; Wang, X.-R.; Zeng, Q.-Y. Extensive Functional Diversification of the Populus Glutathione S-Transferase Supergene Family. Plant Cell 2009, 21, 3749-3766. [CrossRef] [PubMed]

57. Guo, A.-Y.; Zhu, Q.H.; Chen, X.; Luo, J.C. GSDS: A gene structure display server. Hereditas 2007, 29, $1023-1026$. [CrossRef]

58. Deng, W.; Wang, Y.; Liu, Z.; Cheng, H.; Xue, Y. HemI: A Toolkit for Illustrating Heatmaps. PLoS ONE 2014, 9, e111988. [CrossRef]

59. Ren, J.; Wen, L.; Gao, X.; Jin, C.; Xue, Y.; Yao, X. DOG 1.0: Illustrator of protein domain structures. Cell Res. 2009, 19, 271-273. [CrossRef]

60. Li, S.; Zhen, C.; Xu, W.; Wang, C.; Cheng, Y. Simple, rapid and efficient transformation of genotype Nisqually-1: A basic tool for the first sequenced model tree. Sci. Rep. 2017, 7, 2638. [CrossRef]

61. Jefferson, R.A.; Kavanagh, T.A.; Bevan, M.W. GUS fusions: Beta-glucuronidase as a sensitive and versatile gene fusion marker in higher plants. EMBO J. 1987, 6, 3901-3907. [CrossRef]

62. Wilkins, O.; Nahal, H.; Foong, J.; Provart, N.J.; Campbell, M.M. Expansion and diversification of the Populus R2R3-MYB family of transcription factors. Plant Physiol. 2009, 149, 981-993. [CrossRef]

63. Sundell, D.; Street, N.R.; Kumar, M.; Mellerowicz, E.J.; Kucukoglu, M.; Johnsson, C.; Kumar, V.; Mannapperuma, C.; Delhomme, N.; Nilsson, O.; et al. AspWood: High-spatial-resolution transcriptome profiles reveal uncharacterized modularity of wood formation in Populus tremula. Plant Cell 2017, 29, 1585-1604. [CrossRef]

64. McCarthy, R.L.; Zhong, R.; Ye, Z.-H. Secondary wall NAC binding element (SNBE), a key cis-acting element required for target gene activation by secondary wall NAC master switches. Plant Signal. Behav. 2011, 6, 1282-1285. [CrossRef]

65. Pyo, H.; Demura, T.; Fukuda, H. TERE; a novel cis-element responsible for a coordinated expression of genes related to programmed cell death and secondary wall formation during differentiation of tracheary elements. Plant J. 2007, 51, 955-965. [CrossRef]

66. Ohashi-Ito, K.; Oda, Y.; Fukuda, H. Arabidopsis VASCULAR-RELATED NAC-DOMAIN6 Directly Regulates the Genes That Govern Programmed Cell Death and Secondary Wall Formation during Xylem Differentiation. Plant Cell 2010, 22, 3461-3473. [CrossRef]

67. Kim, W.-C.; Ko, J.-H.; Han, K.-H. Identification of a cis-acting regulatory motif recognized by MYB46, a master transcriptional regulator of secondary wall biosynthesis. Plant Mol. Biol. 2012, 78, 489-501. [CrossRef]

68. Zhong, R.; Ye, Z.H. MYB46 and MYB83 Bind to the SMRE Sites and directly activate a suite of transcription factors and secondary wall biosynthetic genes. Plant Cell Physiol. 2012, 53, 368-380. [CrossRef]

69. Park, G.-G.; Park, J.-J.; Yoon, J.; Yu, S.-N.; An, G. A RING finger E3 ligase gene, Oryza sativa Delayed Seed Germination 1 (OsDSG1), controls seed germination and stress responses in rice. Plant Mol. Biol. 2010, 74, 467-478. [CrossRef]

70. Hervé, C.; Lefebvre, B.; Cullimore, J. How many E3 ubiquitin ligase are involved in the regulation of nodulation? Plant Signal. Behav. 2011, 6, 660-664. [CrossRef]

71. Liu, Q.G.; Yang, J.L.; Wang, Z.C.; Xu, X.M.; Mao, X.L.; Li, D.D.; Hu, X.Q.; Jin, D.C.; Li, C.H. Genome-wide classification, identification and expression profile of the C3HC4-type RING finger gene family in poplar (Populus trichocarpa). Plant Mol. Biol. Rep. 2015, 33, 1740-1754. [CrossRef]

72. Kumar, M.; Campbell, L.; Turner, S. Secondary cell walls: Biosynthesis and manipulation. J. Exp. Bot. 2016, 67, 515-531. [CrossRef]

(C) 2019 by the authors. Licensee MDPI, Basel, Switzerland. This article is an open access article distributed under the terms and conditions of the Creative Commons Attribution (CC BY) license (http://creativecommons.org/licenses/by/4.0/). 